\title{
Wear characteristics in turning high hardness alloy steel by ceramic and $\mathrm{CBN}$ tools
}

\author{
S.Y. Luo ${ }^{\text {a,* }}$, Y.S. Liao ${ }^{\text {b }, Y . Y . ~ T s a i ~}{ }^{\text {b }}$ \\ a Department of Mechanical Engineering, Huafan University, Shihtin, Taipei, Taiwan, ROC \\ ${ }^{\mathrm{b}}$ Department of Mechanical Engineering, National Taiwan University, Taipei, Taiwan, ROC
}

Received 24 October 1997

\begin{abstract}
The wear behaviour in the turning of AISI 4340 hardened alloy steels by CBN and ceramic tools was studied. Experimental results showed that the main wear mechanism for the CBN tools was the abrasion of the binder material by the hard carbide particles of the workpiece. For the ceramic tools, there was adhesive wear and abrasive wear. It was also found that there was a protective layer formed on the chip-tool interface. For the $\mathrm{CBN}$ tool, this was a solution of the binder of the tool material and the work material, while for the ceramic tool, this was from the work material. This layer plays a very important role in the wear behavior of CBN and ceramic tools. Variations of tool wear with the cutting speed and the hardness of the work material are discussed accordingly. (C) 1999 Elsevier Science S.A. All rights reserved.
\end{abstract}

Keywords: High hardness alloy steel; CBN tool; Ceramic tool; Wear

\section{Introduction}

CBN and ceramic tools are widely used in the metalworking industry for the cutting of various hard materials such as alloy steels, high-speed tool steels, die steels, bearing steels, case-hardened steels, white cast iron, and alloy cast irons. In many applications, the cutting of ferrous materials in their hardened condition can replace grinding to give significant savings in cost and increase in productivity. However, pre-requisites for the successful machining of hardened ferrous alloys may include: the use of an extremely rigid and high-precision machine tool system; a very hard and tough tool material; a negative rake tool geometry with a high wedge angle, a strong shape and an appropriate chamfer or radius, honed at the cutting edge; tool holders with high stiffness; and appropriate cutting conditions [1].

Various studies have been conducted to investigate the performance of CBN and ceramic tools in the machining of various hard materials. Nakayama et al. [2] indicated that cutting forces in the machining of hard materials are not necessarily high compared with those of soft materi-

* Corresponding author. Fax: + 886-2-26631119. als. A high shear angle and the formation of saw-toothed chips due to poor ductility reduce the forces despite the high strength of hard materials. In addition, tool wear due to abrasion and high temperature in the machining of hard materials increases the cutting forces, especially the thrust force.

Ohtani and Yokagawa [3] stated that the main wear mechanism of CBN and ceramic tools in the machining of cold work tool steel SKD11 is abrasion by hard alloy carbide particles contained in the workpiece. The lifespan of carbide tools decreases as workpiece hardness increases, while the lifespan of $\mathrm{CBN}$ and ceramic tools show the opposite results.

Narutaki and Yamane [4] showed that the average cutting temperature of $\mathrm{CBN}$ tools was lower than that of carbide tools, and it decreased with the increase of workpiece hardness when the hardness exceeds a particular limit. The possibility of diffusion wear of CBN tool seems to be relatively low since the cutting temperature is not high enough and CBN grain is chemically stable for iron. Enomoto et al. [5] indicated that in the turning of $\mathrm{Cr}-\mathrm{Mo}$ steels of various hardness, $\mathrm{CBN}$ tools have the shortest life when the steel is rather soft (HRC35), whereas carbide tools showed shorter life with the increase of work material hardness. 
Table 1

Turning conditions

Tool

Cutting speed, $V_{\mathrm{c}}\left(\mathrm{m} \min ^{-1}\right)$

Feed, $f$ (mm per revolution)

Depth of cut, $d$ (mm)

Work material

Cutting fluid

Tool geometry

Inserts

CBN, ceramic, carbide $\mathrm{P} 10$

$60,100,200$

$0.1,0.2 .0 .3$

$0.2,0.5$

AISI 4340

None (dry)

$-6,-6,6,6,30,0,0.8$

TNMG160408 (P10)

TNMA160408 (CBN, ceramic)

(Chamfer $-25^{\circ} \times 0.2 \mathrm{~mm}$ )

Table 2

Properties of the cutting tools ${ }^{\mathrm{a}}$

\begin{tabular}{llll}
\hline Tool types & CBN & Ceramic & Carbide P10 \\
\hline $\begin{array}{l}\text { Density }\left(\mathrm{g} \mathrm{cm}^{-3}\right) \\
\text { Hardness (HV) }\end{array}$ & 4.1 & 4.2 & 10.3 \\
$\begin{array}{l}\text { Transverse rupture strength } \\
\quad\left(\mathrm{kgf} \mathrm{mm} \mathrm{mm}^{-2}\right)\end{array}$ & 110 & 90 & 173 \\
$\begin{array}{l}\text { Elastic modulus }\left(\times 10^{4} \mathrm{kgf} /\right. \\
\left.\mathrm{mm}^{2}\right)\end{array}$ & 5.7 & 4.2 & 5.2 \\
\hline
\end{tabular}

a $\left(1 \mathrm{kgf} \mathrm{mm}^{-2}=9.81 \mathrm{MPa}\right)$.

Even though some studies related to wear conditions and the performance of $\mathrm{CBN}$ and ceramic tools in the cutting of materials of various hardness have been conducted [6-9], the behavior of cutting tools has not been thoroughly understood. In this paper, the investigation of the wear behavior and cutting performance of CBN and ceramic tools in the dry cutting of alloy steels AISI 4340 having various hardness is presented. The cutting forces, cutting temperature, and the SEM examination of the tool during cutting are also discussed.

\section{Experimental procedures}

Dry turning tests were conducted under the conditions shown in Table 1. The tools tested were CBN tools (TiC and $\mathrm{Al}_{2} \mathrm{O}_{3}$ bonds) and ceramic tools $\left(\mathrm{Al}_{2} \mathrm{O}_{3}\right.$

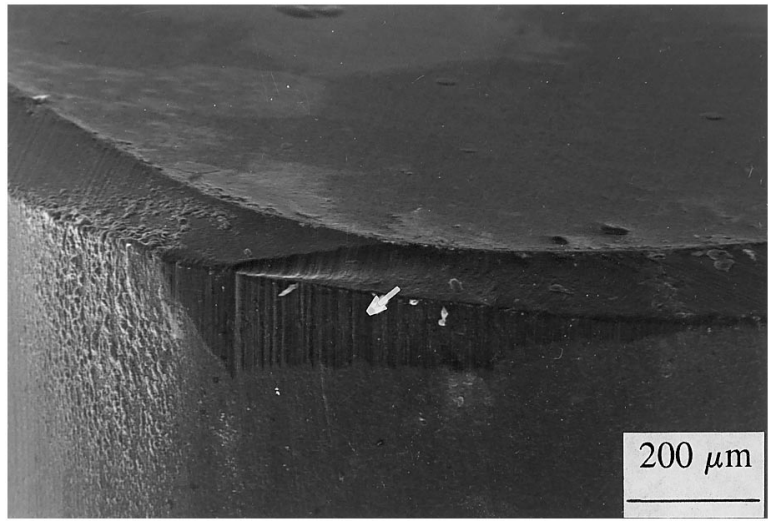

Fig. 1. SEM photograph of the worn appearance of a CBN tool in the machining of AISI 4340 of hardness HRC55 for $5 \mathrm{~min}$.

and $\mathrm{TiC}$ ), their properties are listed in Table 2. For comparison purposes, the carbide tool P10 available on the market was also used. The work material was alloy steel AISI 4340, its heat treatment conditions and hardness are shown in Table 3.

Tool flank wear was measured by means of a toolmakers microscope. A scanning electron microscope (SEM) with energy dispersion analysis of X-ray (EDAX) was used to examine the nature of the worn tool.

The cutting forces were measured by means of a quartz piezoelectric type dynamometer (KISTLER type 9257B) connected to an A/D converter and a personal computer. An infrared pyrometer was used to measure the cutting temperature.

\section{Experimental results and discussion}

\subsection{Tool wear characteristics}

SEM observation of the CBN tool face after the turning of AISI 4340 of hardness HRC55 for $5 \mathrm{~min}$ reveals some grooves with abrasive traces (arrow in Fig. 1), this being typical abrasion wear. The cause of this appearance may be that the binder of the tool is

Table 3

Composition and heat treatment of AISI 4340

\begin{tabular}{|c|c|c|c|c|c|c|c|c|c|c|}
\hline $\begin{array}{l}\text { Composition } \\
\left(w t^{\circ} \%\right)\end{array}$ & $\begin{array}{l}\mathrm{C} \\
0.41\end{array}$ & $\begin{array}{l}\mathrm{Fe} \\
\text { rem }^{\mathrm{b}}\end{array}$ & $\begin{array}{l}\mathrm{Ni} \\
1.65\end{array}$ & $\begin{array}{l}\mathrm{Cr} \\
0.74\end{array}$ & $\begin{array}{l}\text { Mo } \\
0.20\end{array}$ & $\begin{array}{l}\mathrm{Cu} \\
0.12\end{array}$ & $\begin{array}{l}\mathrm{Mn} \\
0.69\end{array}$ & $\begin{array}{l}\mathrm{Si} \\
0.28\end{array}$ & $\begin{array}{l}\mathrm{P} \\
0.017\end{array}$ & $\begin{array}{l}\mathrm{S} \\
0.013\end{array}$ \\
\hline $\begin{array}{l}\text { Heat-treatment conditions } \\
870^{\circ} \mathrm{C} / \mathrm{OQ}^{\mathrm{a}}, 576^{\circ} \mathrm{C} \times 8 \mathrm{~h} \\
870^{\circ} \mathrm{C} / \mathrm{OQ}, 420^{\circ} \mathrm{C} \times 8 \mathrm{~h} \\
870^{\circ} \mathrm{C} / \mathrm{OQ}, 310^{\circ} \mathrm{C} \times 8 \mathrm{~h} \\
870^{\circ} \mathrm{C} / \mathrm{OQ}, 215^{\circ} \mathrm{C} \times 8 \mathrm{~h} \\
870^{\circ} \mathrm{C} / \mathrm{OQ}\end{array}$ & $\begin{array}{l}\text { Work hardness } \\
\text { HRC35 } \\
\text { HRC45 } \\
\text { HRC50 } \\
\text { HRC55 } \\
\text { HRC45 }\end{array}$ & & & & & & & & & \\
\hline
\end{tabular}

\footnotetext{
${ }^{a} \mathrm{OQ}$, oil quenching.

${ }^{\mathrm{b}}$ rem, remainder.
} 

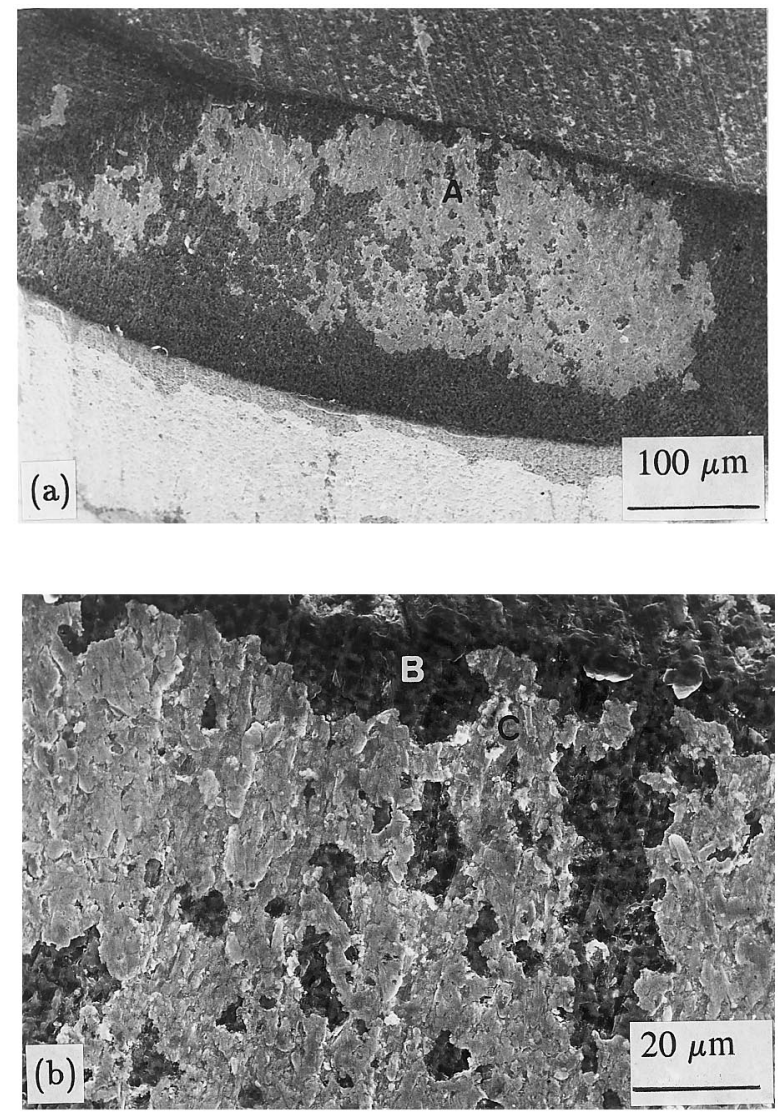

Fig. 2. (a) The worn appearances of a $\mathrm{CBN}$ tool in the machining of AISI 4340 of hardness HRC50 for 5 min; (b) magnification of site A in (a).

abraded by hard carbide particles of the workpiece material, which leads $\mathrm{CBN}$ grains to be detached from the bond. Furthermore, the CBN tool face after turning AISI 4340 of hardness HRC50 for 5 min reveals that there is a layer formed on the cutting edges (Fig. 2(a)). Further examination of the layer at a higher magnification is shown in (Fig. 2(b)). It can be seen that this layer seems to be a solution of materials. Its elements using EDAX are shown in Fig. 3. Comparing elements of the covered layer (hidden line ) with elements of the

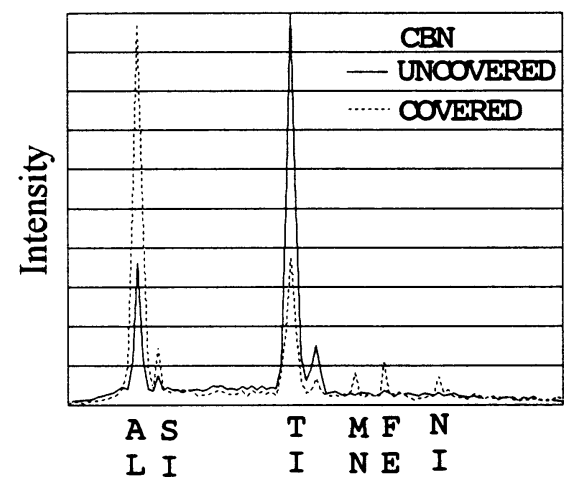

Fig. 3. Element analysis of the tool face of Fig. 2(b).
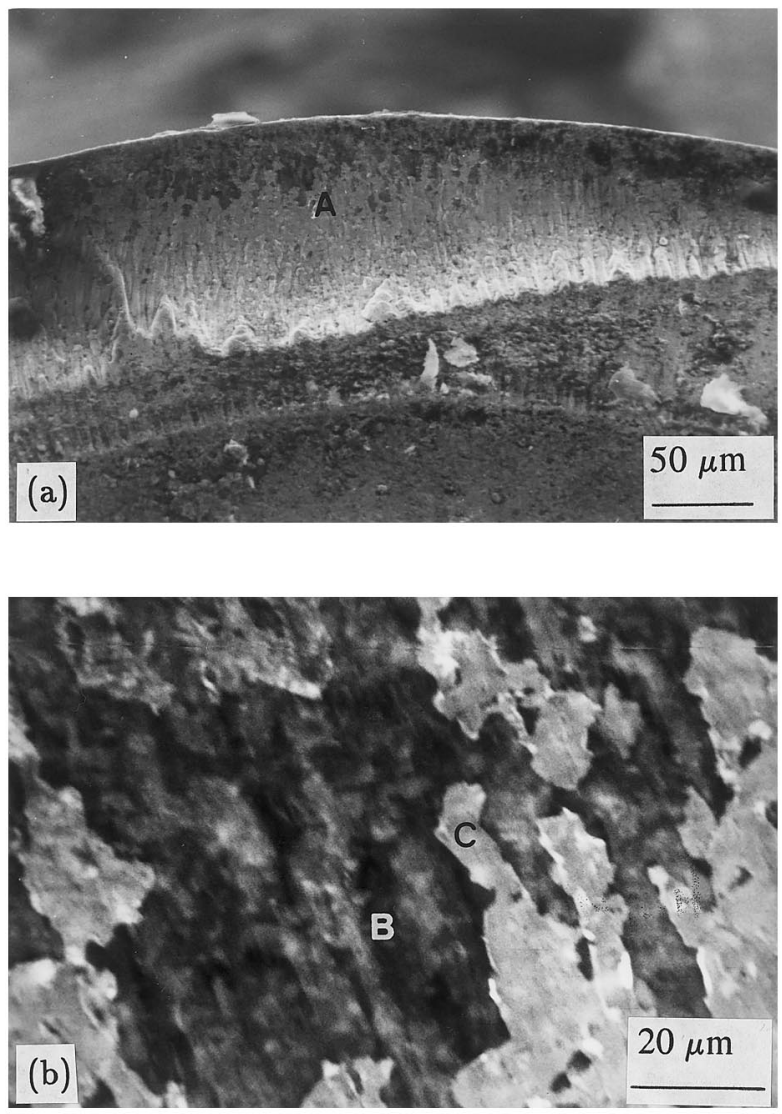

Fig. 4. (a) The worn appearance of a ceramic tool in the machining of AISI 4340 of hardness HRC50 for $5 \mathrm{~min}$; (b) magnification of site $\mathrm{A}$ in (a).

uncovered layer (solid line), it was found that the additional composition of the layer are $\mathrm{Fe}, \mathrm{Ni}$ and $\mathrm{Mn}$ of the workpiece material. In addition, the intensity of A1 on the layer is much stronger than that of the uncovered layer, while the intensity of $\mathrm{Ti}$ on the layer is weaker than that of the uncovered layer. These elements (A1 and Ti) are the binder of the CBN tool. Hence this implies that there is the solution of the work material on the binder of the tool material. Furthermore, it was found that there are some pits (site B of Fig. 2(b)) on the worn face covered by the layer (site C of Fig. 2(b)) and this layer can make use of the pits to reduce its deterioration.

The wear characteristics of the rake face of the ceramic tool after turning alloy steel 4340 of hardness HRC50 for 5 min are shown in Fig. 4(a), and further observation of the higher magnification of site A in Fig. 4(a) are shown in Fig. 4(b). It can be seen that there are some abrasive traces (site B of Fig. 4(b)) and a layer (site A of Fig. 4(a)) adhered to the cutting edges. This wear behavior is typical abrasion and adhesion. The layer deposited on the tool face as detected using EDAX analysis is mainly from the iron element of the work material. These layers (site C of Fig. 4(b)) cover 
some abrasive grooves. This layer can reduce the deterioration of some grooves or pits during cutting, hence it has a protective action, which reduces tool wear and improves tool life. However, when the layer is removed by severe abrasive action, the tool wear is increased. In addition, when a workpiece of hardness HRC60 is turned, there is qualitatively a reduced amount of the layer deposited on the tool rake face (Fig. 5).

The flank wear curves for each tool with cutting time in the machining alloy steel 4340 of various hardness at a cutting speed of $100 \mathrm{~m} \mathrm{~min}^{-1}$, a feed of $0.1 \mathrm{~mm}$ per revolution, and a depth of cut of $0.2 \mathrm{~mm}$ are shown in Fig. 6(a)-(e). As can be seen in these figures, the flank wear of P10 carbide tool when cutting 4340 steels having lower hardness of HRC35 and 45 for $5 \mathrm{~min}$ is about 0.1 and $0.5 \mathrm{~mm}$, respectively. However, the P10 tool in cutting a workpiece hardness above HRC45 can not survive for $5 \mathrm{~min}$, and fracture of the cutting edge takes place. At a higher work hardness of HRC55 or 60, the P10 carbide tool fails almost immediately, its usable cutting time is less than $1 \mathrm{~min}$. This may be the result of high local stress and high temperature on the cutting edges. It shows that the sintered carbide P10 tool is more suitable for turning a workpiece of lower hardness. However, CBN and ceramic tools have a low flank wear.

A wear curve of each tool in the machining of alloy steel 4340 of hardness HRC60 is shown in Fig. 7. It can be seen that the ceramic tool can survive for about 30 min, but thereafter it fractures. However, the CBN tool has a longer life, which may be because the transverse rupture strength of the ceramic tool is lower (see Table 2 ). The lifespan of carbide P10 is very short in the cutting of high hardness steel, this implies that ceramic (alumina oxide and $\mathrm{TiC}$ ) and $\mathrm{CBN}$ tools are acceptable for the cutting of high hardness alloy steels.

\subsection{Effect of cutting speed on tool life}

The variation of tool life for each tool with the

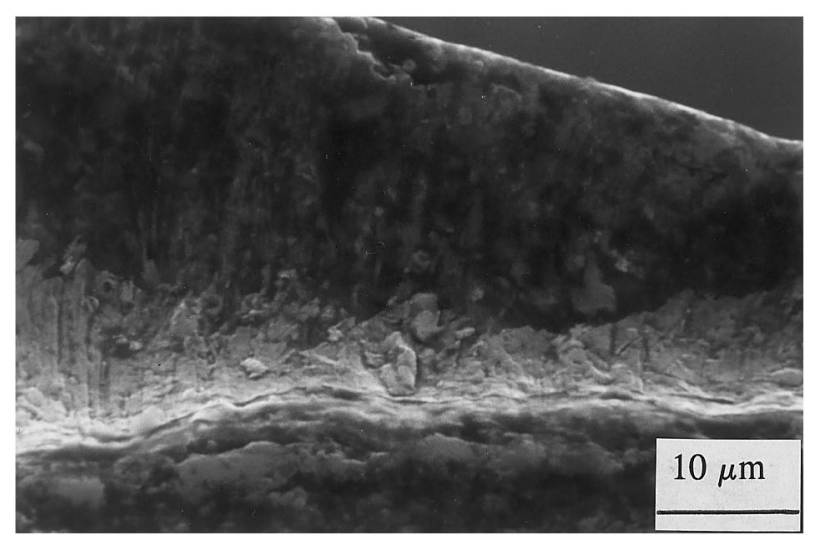

Fig. 5. Worn appearance of a ceramic tool in the machining of AISI 4340 of hardness HRC60 for $5 \mathrm{~min}$. increase of cutting speed in the turning of 4340 alloy steel of hardness HRC60 at a feed of $0.1 \mathrm{~mm}$ per revolution and a depth cut of $0.2 \mathrm{~mm}$ is shown in Fig. 8. It can be seen that the resultant tool life for the P10 tool is very poor. This may be due to the high hardness of the work material which causes high cutting forces and high cutting temperature. Hence, it leads the P10 carbide tool to suffer rapid wear, chipping, or fracture. However, the tool life for CBN and ceramic tools is increased with cutting speed until it reaches a maximum value, and thereafter the tool life starts to decrease. The reason for this may be that the amount of the adhered layer (based on the qualitative observation) increases with the increase of cutting speed, and acts as a protective film to reduce tool wear, which leads to an increase of the tool life with the cutting speed. However, when the cutting temperature is very high due to a high cutting speed, the layer on the tool face becomes soft. Under such conditions, it can be easily abraded by the hard particles of the work material, and tool wear is accelerated. Thereafter, the life of ceramic and CBN tools would rapidly be reduced.

\subsection{Effect of hardness of workpiece on tool wear}

The flank wear of each tool after cutting 4340 alloy steel of various hardness for $5 \mathrm{~min}$ at a cutting speed of $100 \mathrm{~m} \mathrm{~min}^{-1}$, a feed of $0.1 \mathrm{~mm}$ per revolution, and a depth of cut of $0.2 \mathrm{~mm}$ is shown in Fig. 9. The flank wear of the P10 tool is lower when the steel has a lower hardness. However, when cutting a higher hardness steel, tool wear increased rapidly. For ceramic and CBN tools, wear is decreased with an increase in hardness of the workpiece until it reaches a certain critical value, and at about HRC50, the wear starts to increase. This wear behaviour may be due to the effect of the cutting forces, and the cutting temperature.

From Fig. 9, it should be noted that the wear of the CBN tool is greater than that of the ceramic tool, which may be the result of the adhering layer on the tool cutting edges, and the solution between the binder of the CBN tool and the workpiece materials (see Fig. 3). This may weaken the bond between the CBN grains and the binder, this can lead the adhered layer becoming more easily removed from the tool face. However, the ceramic tool is chemically stable for the $\mathrm{Ni}$ and $\mathrm{Fe}$ elements of the workpiece. Hence, a layer can be formed more easily on the tool face based on qualitative observation (refer to Fig. 4). Since the adhered layer on the ceramic tool face has a better protective action, tool war is smaller and tool life is greater.

The variation of the cutting forces with the hardness of the work material for $\mathrm{CBN}$ and ceramic tools is consistent with the variation of the tool flank wear as shown on Fig. 10. It can be seen that the principal 


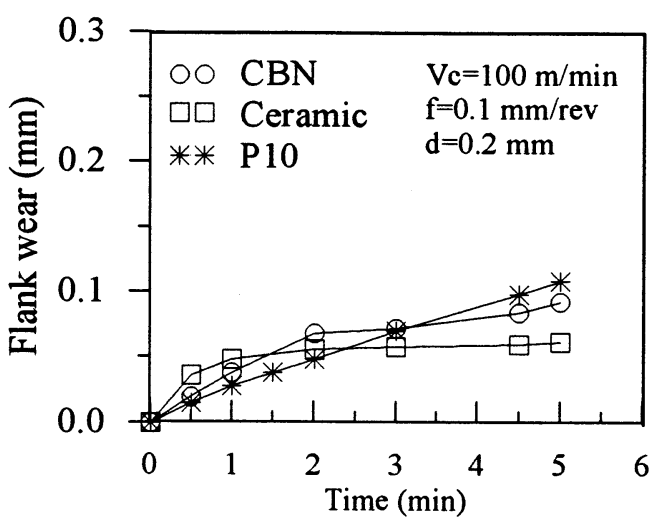

(a) AISI 4340 (HRC35)

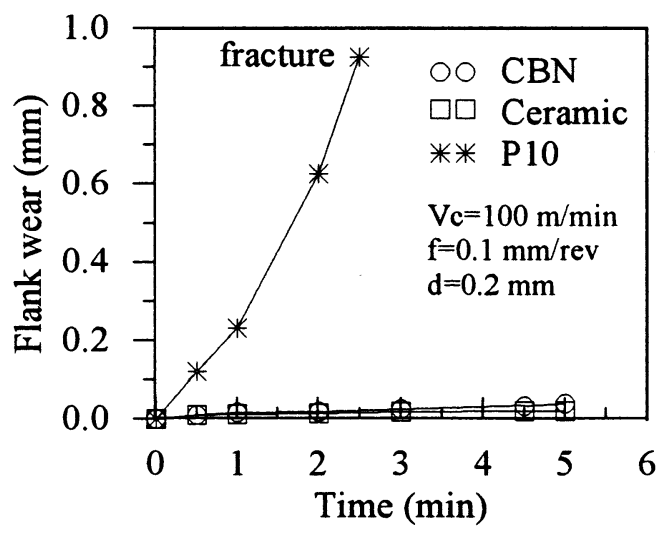

(c) AISI 4340 (HRC50)

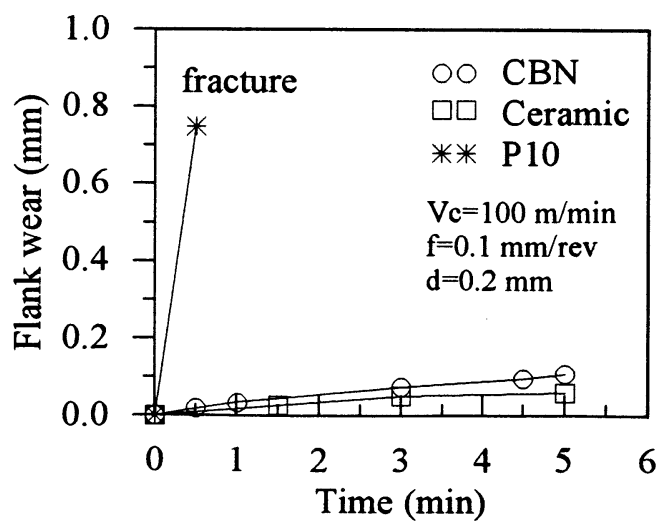

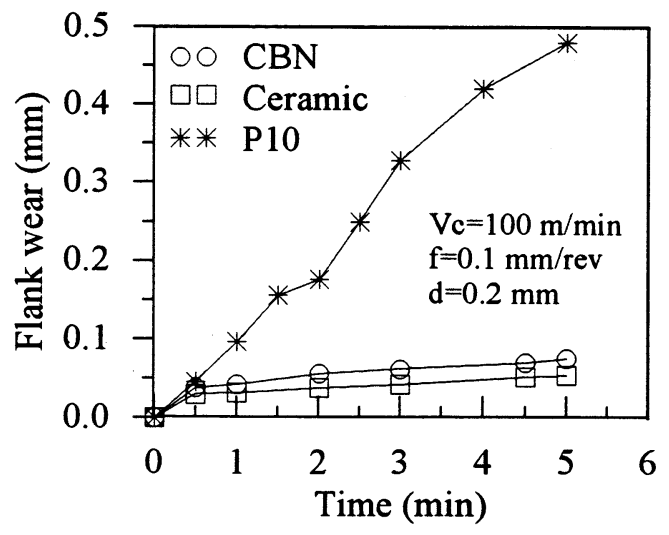

(b) AISI 4340 (HRC45)

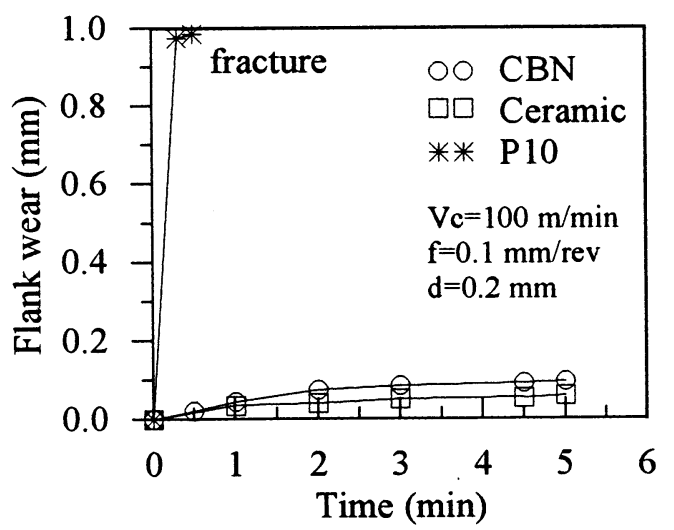

(d) AISI 4340 (HRC55)

(e) AISI 4340 (HRC60)

Fig. 6. Flank wear curves of various tools with cutting time in the machining of AISI 4340 of hardness: (a) HRC35; (b) HRC45; (c) HRC50; (d) HRC55; and (e) HRC60.

cutting force and thrust force decreased with the increase of hardness, and at about HRC50, the cutting force starts to increase. The cutting forces for the ceramic tool are greater than those of the CBN tool. In addition, a high temperature in cutting can be reach due to the smaller thermal conductivity of ceramic tools. Hence, the adhesive force in the chip-tool con- tact would be larger. This causes the deposited layer on the cutting edges to form more easily (refer to Fig. 4). The protective layer would reduce the abrasive wear of the tool, hence its flank wear is smaller (Figs. 6 and 8).

The variation of the cutting temperature with the hardness of the work material is also shown in Fig. 11. In the case of the $\mathrm{CBN}$ tool, a cutting temperature of 


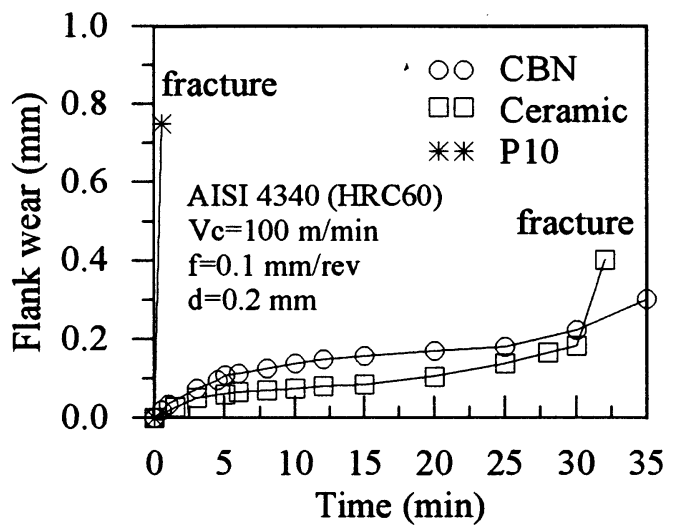

Fig. 7. Wear curves of various tools in the machining of AISI 4340 of hardness HRC60.

about HRC50 is maximum. Its temperature curve is inversely related to the cutting forces and the tool wear. This phenomenon may be related to the chip-formation mechanism. Fig. 12(a)-(d) shows the longitudinal section of chips produced for various hardened 4340 steels. The chip formed during cutting for lower hardness work material is mainly produced by plastic deformation, the energy required during cutting increasing proportionally with the increase of hardness. This would cause the cutting temperature to increase with the increase of work hardness. However, when the workpiece hardness exceeds about HRC50, the chip produced becomes thinner and its shape changes from flow type to saw-tooth type (Fig. 12(b)-(d)). This phenomena has also been reported by Narutaki and Yamane [4] and Komanduri et al. [10]. Furthermore, the shear angle during cutting increases with the increase of hardness (Fig. 13). The reduction of chip thickness with the increase of work hardness results from the increase of shear angle. The chips are subjected to severe deformation, and the heat generated during cutting flows mostly into the chip. The high temperature would concentrate on the local shear band of the chip. Hence, a saw-tooth

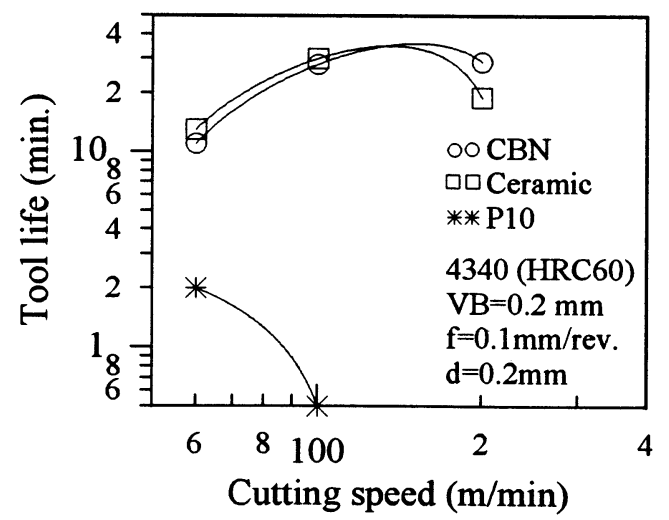

Fig. 8. Variation of tool life with cutting speed in the machining of AISI 4340 of hardness HRC60.

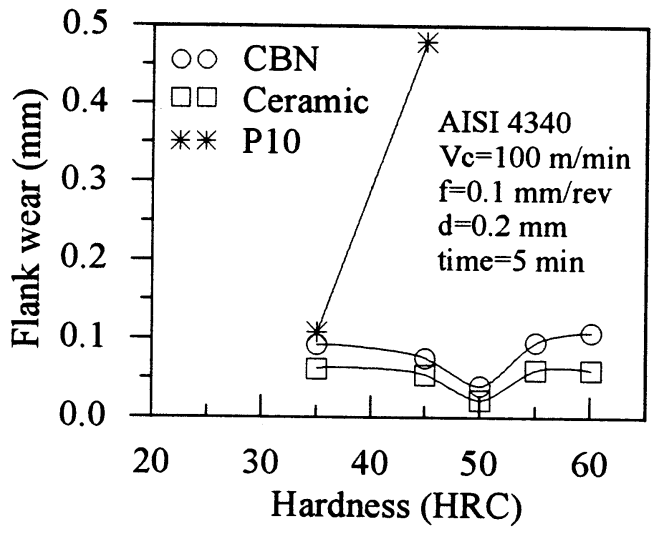

Fig. 9. Flank wear curves of various tools with hardness of workpiece after machining AISI 4340 for 5 min.

chip is formed. Moreover, when the hardness of the work material turned becomes larger, the material is more brittle, which in turn causes the fracture energy required during cutting to be smaller. This leads to the chip more readily developing a saw-tooth appearance. Once this happens, the cutting temperature would not increase, instead it starts to decrease.

However, the saw-tooth chip can not be formed for the carbide P10 tool due to smaller deformation and larger chip thickness. Therefore, its cutting temperature increases with the increase of work hardness (see Fig. 11).

To be more specific, when turning work of hardness below HRC50 by ceramic and CBN tools, the cutting temperature is increased with the increase of the work material hardness. This causes the workpiece to become softer, so that the cutting forces produced are decreased. Furthermore, the adhesive force of the chip/ tool interface at the higher temperature would increase, which can cause the adhered layer on the tool face to increase (Figs. 2 and 4), which in turn protects the cutting edges and reduces tool wear. However, in the

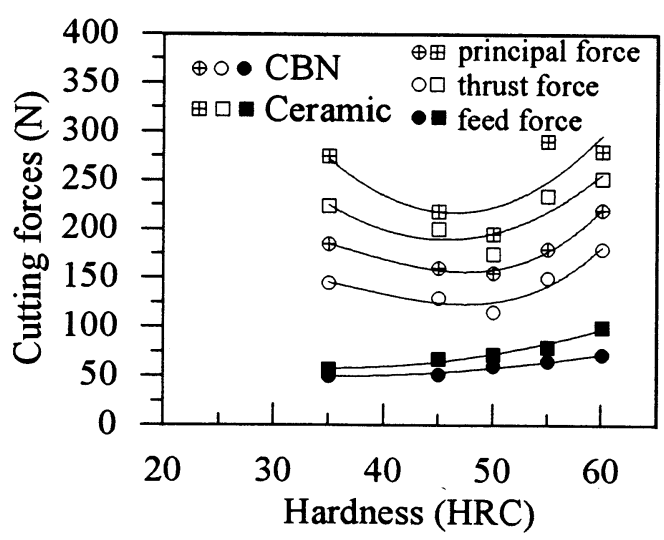

Fig. 10. Variation of cutting forces with hardness of workpiece in machining AISI 4340 . Cutting speed: $100 \mathrm{~m} \mathrm{~min}^{-1}$; feed: $0.1 \mathrm{~mm}$ per revolution; depth of cut: $0.2 \mathrm{~mm}$. 


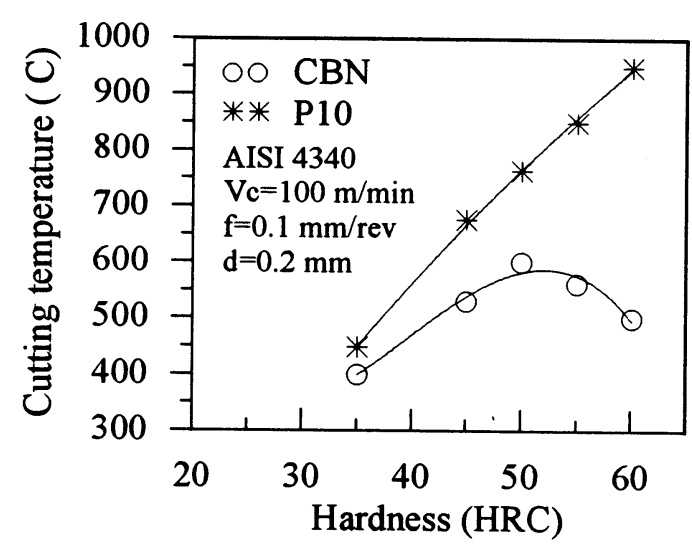

Fig. 11. Variation of the cutting temperature with hardness of workpiece in the machining of AISI 4340.

case of turning work material of hardness above HRC50, the saw-tooth chip is gradually produced, and the cutting temperature starts to decrease. Then, the degree of softening of the workpiece is smaller, and there is less adhered layer on the tool face (Figs. 1 and 5). Moreover, high shear stress and strain on the saw-tooth chip are produced. Hence, the cutting force starts to increase, and tool wear also becomes larger (refer to Figs. 9 and 10).

\section{Conclusions}

Based on these experimental results, the following conclusions can be drawn:
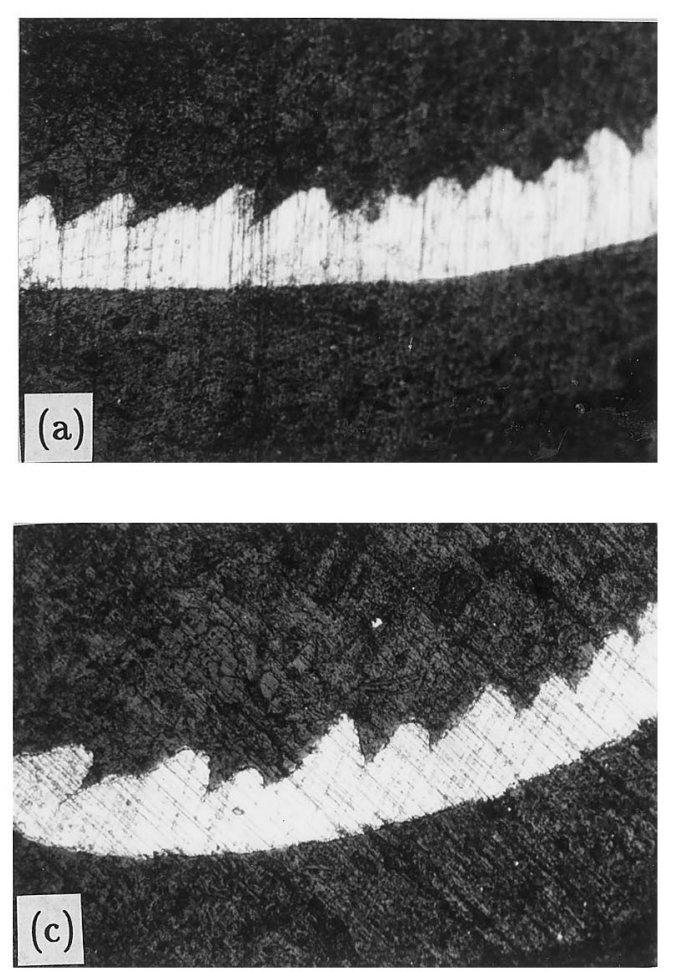

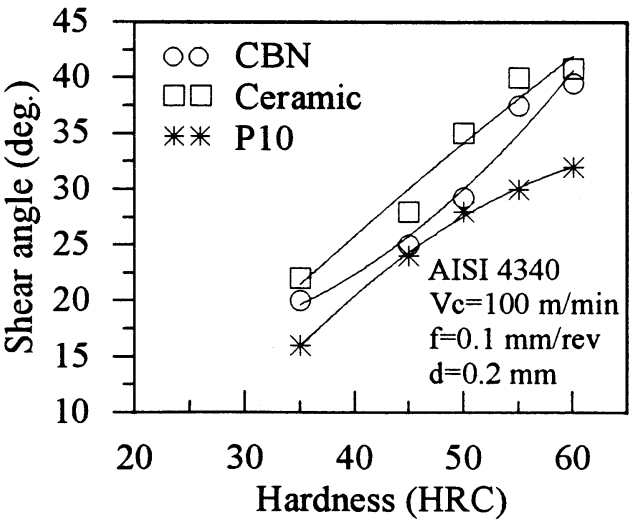

Fig. 13. Variation of shear angle with the hardness of workpiece in the machining of AISI 4340.

(1) The main wear mechanism for CBN tools is the abrasion of the binder material by hard carbide particles of the workpiece. For the ceramic tools, there is adhesion wear and abrasion wear.

(2) The increase of tool life with the cutting speed for CBN and ceramic tools could result from a protective layer formed on the chip-tool interface. For the CBN tool, it was the solution of the binder of the tool material, while for the ceramic tool it was the work material. However, when the temperature is very high due to a greater cutting speed, the layer on the tool face becomes soft. Hence, it would be easily abraded by the hard particles of the work material, so that tool wear would be accelerated.
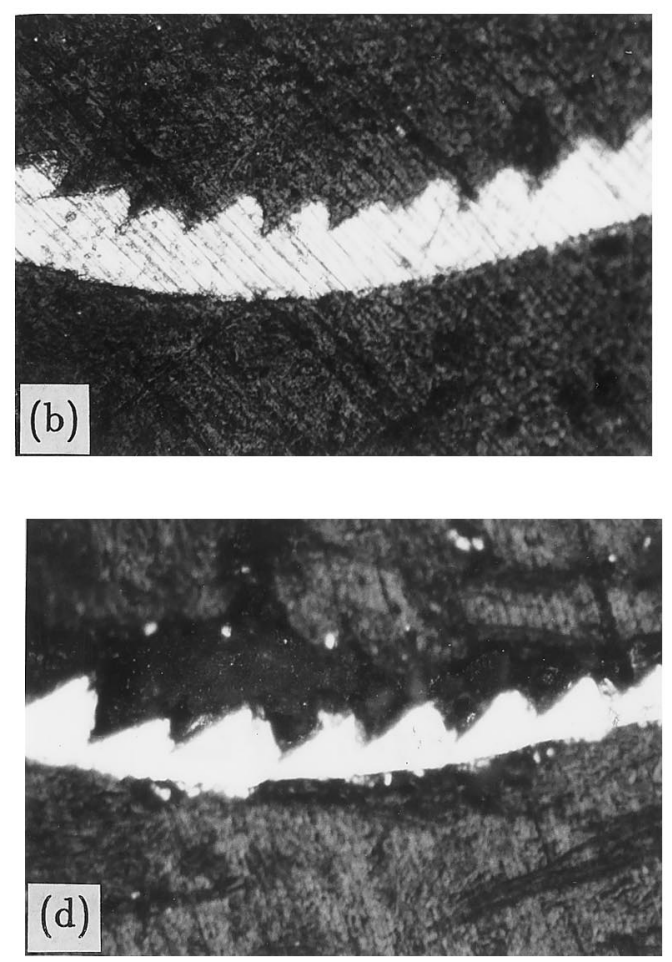

Fig. 12. Chip appearance in the machining of AISI 4340 of hardness: (a) HRC45; (b) HRC50; (c) HRC55; (d) HRC60. 
(3) The wear of ceramic and CBN tools is decreased with an increase of hardness, but at about HRC50 the wear started to increase. This behavior is consistent with the variation of the cutting force, which in turn was inversely related to the cutting temperature.

\section{References}

[1] W. König, R. Komanduri, H.K. Tönshoff, G. Ackerschott, Machining of hard materials, Ann. CIRP 32 (2) (1984) 417427.

[2] K. Nakayama, M. Arai, T. Kanda, Machining characteristics of hard materials, Ann. CIRP 37 (1) (1988) 89-92.

[3] T. Ohtani, H. Yokogawa, The effects of workpiece hardness on tool wear characteristics, Bull. Jpn. Soc. Precis. Eng. 22 (3) (1988) 229-231.

[4] N. Narutaki, Y. Yamane, K. Okushima, Tool wear and cut- ting temperature of $\mathrm{CBN}$ tools in machining of hardened steels, Ann. CIRP 28 (1) (1979) 23-28.

[5] S. Enomoto, M. Kato, S. Miyazawa, T. Ono, Characteristics of tool life of CBN cutting tool in turning chromium-molybdenum steels of various hardness, Bull. Jpn. Soc. Precis. Eng. 21 (3) (1987) 209-210.

[6] N. Gane, W. Stephens, The wear and fracture characteristics of ceramic cutting tools, Wear 88 (1983) 67-83.

[7] K. Oishi, T. Nishida, Study on the fracture characteristics of ceramic cutting tools (1st report), Wear 154 (1992) 361-370.

[8] W. König, M. Klinger, R. link, Machining hard materials with geometrically defined cutting edge-field of application and limitations, Ann. CIRP 39 (1) (1990) 61-64.

[9] Y. Matsumoto, M.M. Barash, C.R. Liu, Cutting mechanism during machining of hardened steel, Mater. Sci. Technol. 3 (1987) 299-305.

[10] R. Komanduri, T.A. Schroeder, J. Hazra, B.F. von Turkovich, D.G. Flom, On the catastrophic shear instability in high speed machining of an AISI 4340 steel, ASME Trans. J. Eng. Ind. 104 (1982) 121-131. 